\title{
Modeling of a Bio-Thermo-Electric Micro-Cooler
}

\author{
Aparna Prabhakar, Michael C. Murphy and Ram V. Devireddy ${ }^{*}$
}

Department of Mechanical Engineering, Louisiana State University, Baton Rouge, USA

\begin{abstract}
This work is a part of an on-going research effort to fabricate a device consisting of an array of micro thermoelectric coolers ( $\mu$ TECs) for highly localized control of temperature in biological systems. A preliminary lumped 1-D parameter model was developed and numerical simulations were carried out to identify the critical and optimal design parameters for a $\mu$ TEC operating under steady state conditions. The lumped parameter analysis revealed the presence of a new limitation on the maximum possible current through the system, which we denoted as the secondary breakdown current (as opposed to the primary breakdown current associated with Joules heating). To further understand the effect of contact resistances (thermal and electrical), radiative effects, and lateral effects (interactions between $\mu$ TECs) in our device, we developed a 3-D finite element model (FEM) using ANSYS ${ }^{\circledR}$. The FEM analysis identified the optimal distance between $\mu$ TECs to generate discrete and distinct temperatures within the cells located in the extracellular matrix and thus, generating the optimal design specifications for our device.
\end{abstract}

\section{INTRODUCTION}

Localized control of temperature at cellular level can be achieved by fabrication of a micro thermoelectric cooler ( $\mu$ TEC). The ability to control temperature locally has the potential to impact many areas of research, including low temperature storage of artificial and native tissues. Specifically, the precise temperature control and spot cooling/heating features of the proposed $\mu$ TEC makes it an ideal choice for enabling temperature modulation of individual cells embedded in an extracellular matrix. This represents a significant advance in our ability to study biological systems with carefully delineated temperature regimes. As a prelude to fabricating this device, it is essential to predict the performance of the integrated cooling object (i.e. biological cell) and a $\mu$ TEC. The performance of the proposed $\mu$ TEC can be enhanced a priori by determining the critical and optimal design parameters conditions and predicting the interplay amongst them.

The first attempt to mathematically describe the operation and the performance of a thermoelectric (TE) device was done by using conventional design theory [1-6]. These preliminary studies assumed that the Seebeck coefficient, $\alpha$, the thermal conductivity, $k$ and the electrical conductivity, $\sigma$ of the TE material were invariant with temperature. Later analyses [7-9] developed a "temperature averaging" methodology for the TE materials in an attempt to partially account for the effects ignored by the conventional design theory. Inaccuracies inherent in the "temperature averaging" methodology were ameliorated by [10-12] who derived dimensionless entropy equations that form a closed form expression for the TE system with heat sinks. This dimensionless entropy model was later used to analyze the optimum design conditions of a TE cooler, thereby forming the basis for most of the design improvements for macro-TEC designs [13-17]. However, the above mentioned design methodologies disregard the effect of the thermal and electrical contact resis-

*Address correspondence to this author at 2508 CEBA Bldg., Dept. of Mechanical Engineering, Louisiana State University, Baton Rouge, LA 70803, USA; Tel: 225578 5891; Fax: 225578 5924;

E-mail: devireddy@me.lsu.edu tances. Although, this assumption of negligible thermal and electrical contact resistance is reasonable for macro TE coolers $(>100 \mu \mathrm{m})$ it's inclusion is essential to accurately model $\mu$ TECs $[18,19]$. A recent model of $\mu$ TEC accounts for contact resistances [20] but is not applicable when the object to be cooled or heated (i.e. passive load) is comparable in size with the $\mu$ TEC. Thus, in the present study we present a lumped parameter model of a $\mu$ TEC interacting with a passive load of comparable size to the desired cooler i.e. integrated biological cell and a single stage $\mu$ TEC. Results from the lumped parameter model were then incorporated into a 3D finite element model (FEM) using ANSYS ${ }^{\circledR}$ to identify the optimal layout of the proposed $\mu$ TEC device.

\section{LUMPED PARAMETER MODEL}

The lumped parameter model follows the approach outlined by [10] and is based on a set of rate equations describing one dimensional thermal dynamics through all intermediate layers, including the ceramics and metal interconnects. Briefly, adiabatic boundary conditions are applied to four side surfaces of the volume control and the symmetry condition is utilized to simplify the analysis of the device to a single $\mu$ TEC leg element sandwiched between two substrates (i.e. ceramic layers) (Fig. 1). The biological cell to be subjected to temperature modulation by the $\mu \mathrm{TEC}$ is simulated as a layer of ice. Various design conditions of the proposed micro TE cooler are analyzed to obtain optimum performance and two "free" variables are arbitrarily chosen: (1) constant temperature difference, $\Delta \mathrm{T}$ or a constant heat load, $\mathrm{Q}$ and (2) the base or the hot junction temperature, $T_{h}$. The problem formulation also accounts for the temperature dependence of various $\mu$ TEC parameters $\alpha, k$ and $\sigma$. A first law analysis of heat transfer from the cold junction to the hot junction of the TEC leads to the following set of modified energy balanced equations:

$$
\begin{aligned}
& Q+k_{i c e}\left(T_{a m b}-T_{c}\right)-k_{u p \dot{v} c e r}\left(T_{c}-T_{1}\right)=0 \\
& k_{u p \dot{v} c e r}\left(T_{c}-T_{1}\right)+k_{A u}\left(T_{2}-T_{1}\right)=0
\end{aligned}
$$


$\alpha I T_{2}-\frac{1}{2} I^{2}\left(R+\frac{r_{c o n}}{2}\right)-k_{A u}\left(T_{1}-T_{2}\right)-k_{T E}\left(T_{3}-T_{2}\right)=0$

$\alpha I T_{3}+\frac{1}{2} I^{2}\left(R+\frac{r_{c o n}}{2}\right)-k_{T E}\left(T_{2}-T_{3}\right)-k_{c u}\left(T_{4}-T_{3}\right)=0$

$k_{c u}\left(T_{3}-T_{4}\right)+k_{\text {low } \dot{V}_{c e r}}\left(T_{h}-T_{4}\right)=0$

where $T_{h}, T_{c}$ and $T_{a m b}$ are the temperatures of the hot junction, the cold junction and the surrounding environment (assumed to be $300 \mathrm{~K}$ ), respectively. $T_{1}, T_{2}$ and $T_{3}, T_{4}$ are the junction (interface) temperatures above and below $T_{c}$ and $T_{h}$ respectively. While $\mathrm{k}_{\mathrm{cu}}$ and $\mathrm{k}_{\mathrm{Au}}$ are the thermal conductivities of the lower (copper) and upper (gold) interconnects respectively. Similarly, $\mathrm{k}_{\text {low }} \dot{\mathrm{v} e r}, \mathrm{k}_{\mathrm{upV} \text { cer }}$ and $\mathrm{k}_{\text {ice }}$ represent the thermal conductivities of the lower ceramic (alumina), upper ceramic (alumina) and ice respectively. The $r_{\text {con }}$ is the electrical contact resistance at the interface of the hot and the cold junctions. Before proceeding to solve the energy balance equations, we chose several dimensions of the $\mu$ TEC based on the cellular system being cooled/heated and ease of microfabrication (see Table 1). In this study, the five model parameters that were optimized based on these initial constraints were the heights of the upper and lower interconnects and the height, width and length of the $\mu$ TEC leg element.

Since, the maximum temperature gradient is experienced in the $\mu$ TEC leg element region, the $\mu$ TEC leg dimensions become an important parameter of design. For ease in modeling (in both lumped and FEA model) the leg element was assumed to be cubical in shape with its lateral dimension (i.e. width) equivalent to the length of the each individual $\mu$ TEC leg element. Therefore only two $\mu$ TEC leg parameters were varied: (i) height of $\mu$ TEC leg element and (ii) length of $\mu$ TEC leg element. A simple analysis showed that minimizing the height of the $\mu$ TEC leg element will increase the $\Delta \mathrm{T}$ across the device, i.e. $\left(T_{h}-T_{c}\right)$ is maximized. However, the smallest achievable $\mu$ TEC leg height is limited by the ability to electroplate the TE material (Bi-Te alloy) uniformly in a recess and through experimentation this minimum height was found to be $20 \mu \mathrm{m}$ with a corresponding $\Delta \mathrm{T}$ of $4 \mathrm{~K}$ (Fig. 2A). An analysis of the model equations with a fixed value of $\mu$ TEC leg height of $20 \mu \mathrm{m}$ shows that a further increase in the predicted $\Delta \mathrm{T}$ can be achieved if the width and length of the $\mu$ TEC are increased (Fig. 2B). However, the proposed application of the device (i.e. attaining localized temperature in biological cells spaced approximately 30 to $50 \mu \mathrm{m}$ apart) places a design constraint on the width and length of the proposed $\mu$ TEC to a maximum value $10 \mu \mathrm{m}$.

Table 1. The Dimensions of the Proposed $\mu$ TEC Device (All Values are in $\mu \mathrm{m}$ 's)

\begin{tabular}{|c|c|c|c|}
\hline & Height & Width & Length \\
\hline Biological Cell (Ice) & 3 & 12 & 40 \\
\hline Upper Ceramic (Alumina) & 5 & 12 & 36 \\
\hline Upper Interconnect (Gold, Au) & $3 *$ & 11 & 32 \\
\hline TE leg element (Bi-Te) & $20^{*}$ & $10^{*}$ & $10^{*}$ \\
\hline Lower Interconnect (Copper, $\mathrm{Cu}$ ) & $3 *$ & 11 & 13 \\
\hline Lower Ceramic (Alumina) & 10 & 12 & 36 \\
\hline Distance between the TE legs & \multicolumn{3}{|c|}{$10 * *$} \\
\hline
\end{tabular}

**Based on an analysis of ANSYS ${ }^{\mathbb{B}}$ FEM model.

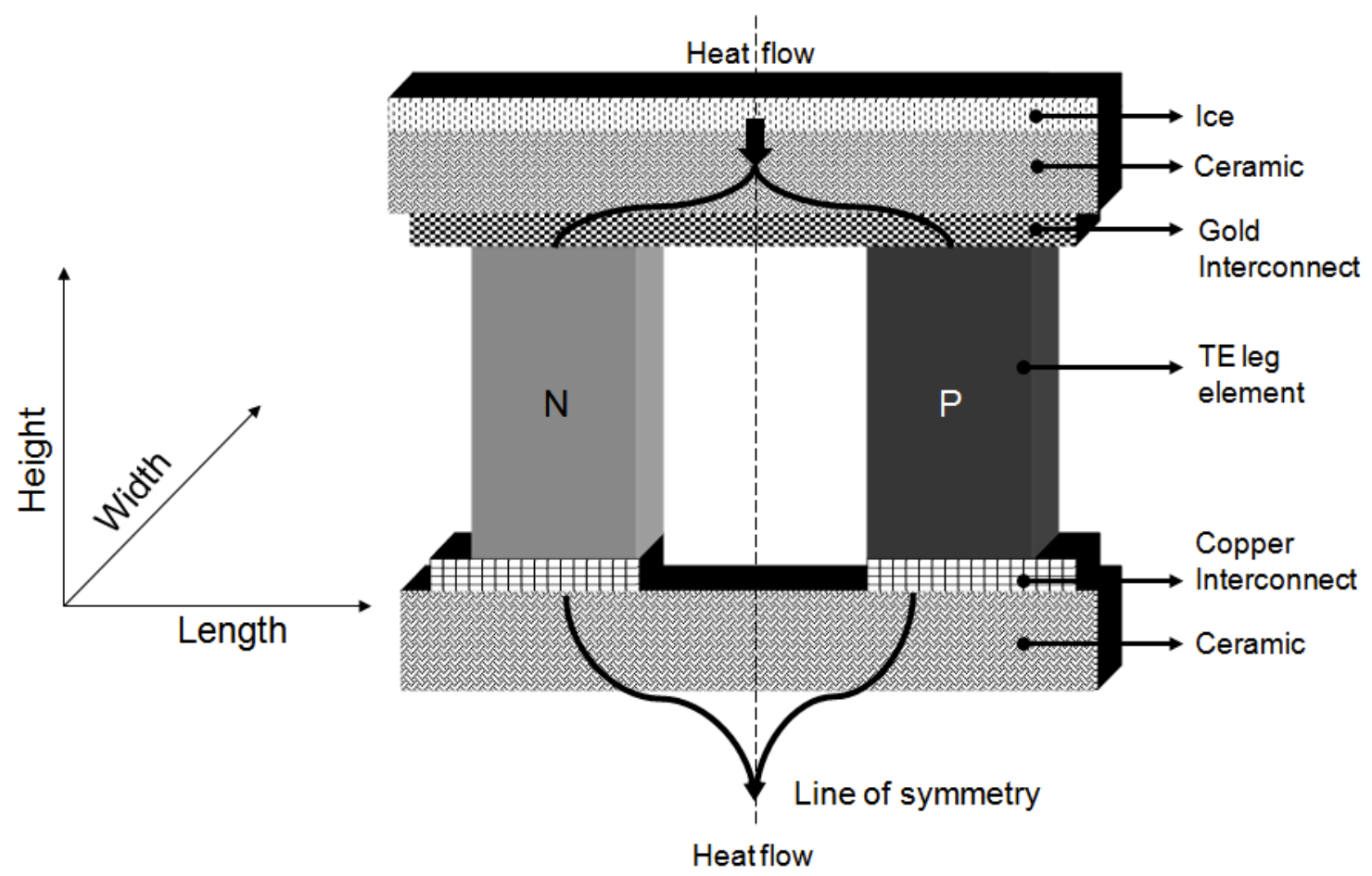

Fig. (1). Schematic of a single stage TEC. In the model, any heat flow between the TE cooler and the ambient surroundings in the direction perpendicular to the line of symmetry is ignored and only the heat transfer along the line of symmetry which accounts for the cooling capacity in the cold end and heat rejection in the hot end is taken into consideration. 

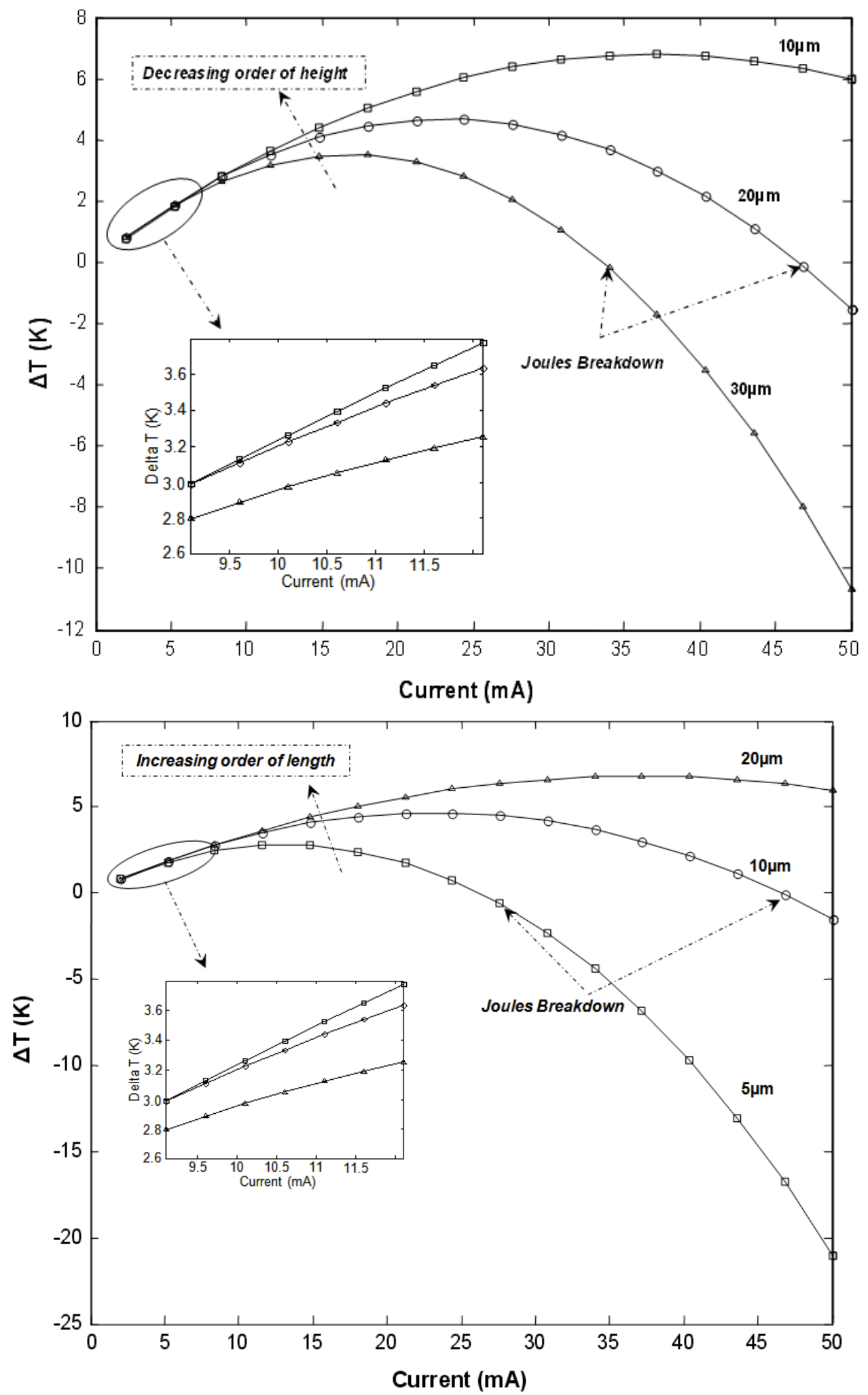

Fig. (2). Influence of the $\mu$ TEC leg element height (Fig. A, top) and $\mu$ TEC leg element length (Fig. B, bottom) at zero external heat load.

After fixing the dimensions $\mu$ TEC leg element (height 20 $\mu \mathrm{m}$, length $=$ width $=10 \mu \mathrm{m})$ it is essential to explore the effect of metal interconnect height on the system. It is observed (Fig. 3A) that the temperature drop increases as the height of interconnect decreases. However to allow for a proper passage of current through the $\mu$ TEC leg elements, the minimum height of interconnects should be $>1 / 10^{\text {th }}$ of the $\mu$ TEC leg element, and was chosen to be $2 \mu \mathrm{m}$. After fixing the height of interconnects, we explored the effect of electrical contact resistance due to the presence of intercon- 
nect on the predicted value of $\Delta \mathrm{T}$. As shown in Fig. 3B, a small increase in contact resistance of the order $10^{-6}$ reduces the maximum achievable temperature drop by $25 \%$ to $3 \mathrm{~K}$. Since the exact value of this electrical contact resistance is dependent upon the fabrication process and cannot be determined a priori, it is expected that the actual $\Delta \mathrm{T}$ in the final device will be less than the model predicted $\Delta \mathrm{T}$.
As evident from Equations (3) and (4) there exists a certain maximum value of current (I) at which the Joules effect starts dominating i.e. the $I^{2} R$ power losses overcome the thermoelectric cooling capacity of the device. The current at which this breakdown occurs is denoted as the Joules breakdown current and is a well established phenomenon in the literature [13-17, 20]. For our device dimensions, the Joules breakdown current was found to be $\sim 46 \mathrm{~mA}$. However, more
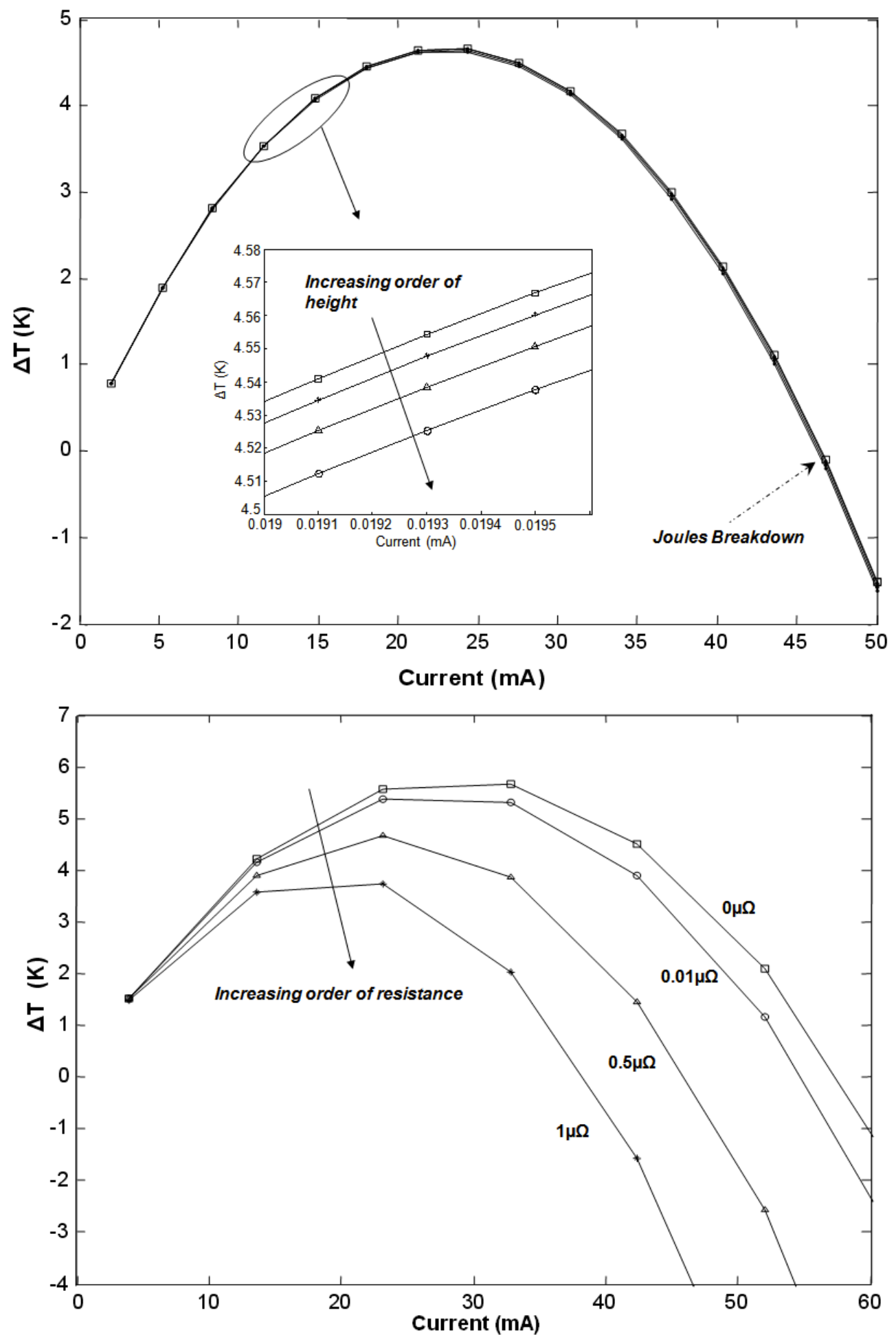

Fig. (3). Influence of the height of metal interconnects (Fig. A, top) and the electrical contact resistance (Fig. B, bottom) at zero external heat load. 
importantly in the $\mu$ TEC we found that imposing a current significantly below the Joules breakdown current can still lead to a thermal breakdown in the ceramic and metallic interconnects (Fig. 4), although not in the $\mu$ TEC leg element. Thus, for $\mu$ TECs the optimal maximum operable current is much lower than the Joules breakdown current and is governed by the dimensions of interconnects rather than the $\mu$ TEC leg element. We denote this new breakdown current as "secondary breakdown current" and found it to be $1.2 \mathrm{~mA}$ (or $\sim 2 \%$ of the Joules breakdown current) in the proposed $\mu$ TEC device. The identification of this secondary breakdown current can help to explain the observed discrepancies between the expected and observed behavior of earlier $\mu$ TECs $[16,19,20]$. These studies assumed that Joules effect is the limiting parameter and did not recognize the presence of a secondary breakdown effect in the metallic interconnects. Therefore for our application it is proposed to vary the current within the range of $0.1-1 \mathrm{~mA}$, well within the secondary breakdown current. Further work is being carried out to verify this experimentally.

Though, the lumped parametric study described above helped us identify the optimal dimensions and the operating conditions for an individual $\mu$ TEC (see Table 1), it does neglect lateral effects (i.e. interaction between $\mu$ TECs). Since the proposed device will eventually consist of an array of individually addressable $\mu$ TECs adjacent to each other it becomes essential to study the interaction between them using 3-D models. Previous 3-D models of TECs [21-23] did not account for the influence of the adjacent TEC on the total heat transfer of the system. In absence of any such previous study, an attempt has been made by us to study the effects of proximity of individual TECs on the total heat transfer through the system. This integrated 3-D thermal-electrical $\mu$ TEC system analysis was performed using ANSYS $^{\circledR}$ (Version 9.1, ANSYS, Inc., Canonsburg, PA). It is important to note that the optimized design parameters obtained from the lumped parameter model were used as a preliminary input to the computationally intensive transient ANSYS ${ }^{\circledR}$ model.

\section{D-FINITE ELEMENT ANSYS ${ }^{\circledR}$ MODEL}

A 3-D thermal system model was constructed using ANSYS $^{\circledR}$ assuming a symmetrical system with $7 \mu$ TECs (Fig. 5), a ramped current pulse in addition to transient-state bias current, temperature dependent Seebeck coefficients and resistivity. Initially, the ANSYS ${ }^{\circledR}$ model was validated using well established results for commercially available macro coefficients, temperature dependent resistivity and temperature dependent conductivity coefficients. The ANSYS model also accounted for heat conduction between individually addressable $\mu$ TECs, Joule's heating within the $\mu$ TECs and thermoelectric cooling due to the $\mu$ TEC as well as other non-ideal effects like contact resistances and heat generation in interconnects. The finite thermal resistance between the object to be cooled (i.e. biological cell) and the $\mu$ TEC was also included in the ANSYS ${ }^{\circledR}$ model. To make the model as close to the final configuration as possible, the whole $\mu$ TEC system was assumed to be embedded within a block of poly methyl-methacrylate (PMMA). The results from the ANSYS ${ }^{\circledR}$ model were used to identify the final parameters in our device, i.e., the distance between $\mu$ TEC leg element and the distance between the $\mu$ TECs in the proposed array.

The initial 3-D ANSYS ${ }^{\circledR}$ analysis indicated that a further increase in the $\Delta T$ values can be achieved by placing the $\mu \mathrm{TEC}$ leg elements as close as possible to each other (Fig. 6A). However the placement of the $\mu$ TEC leg elements is limited by fabrication constraints, which limits the closest

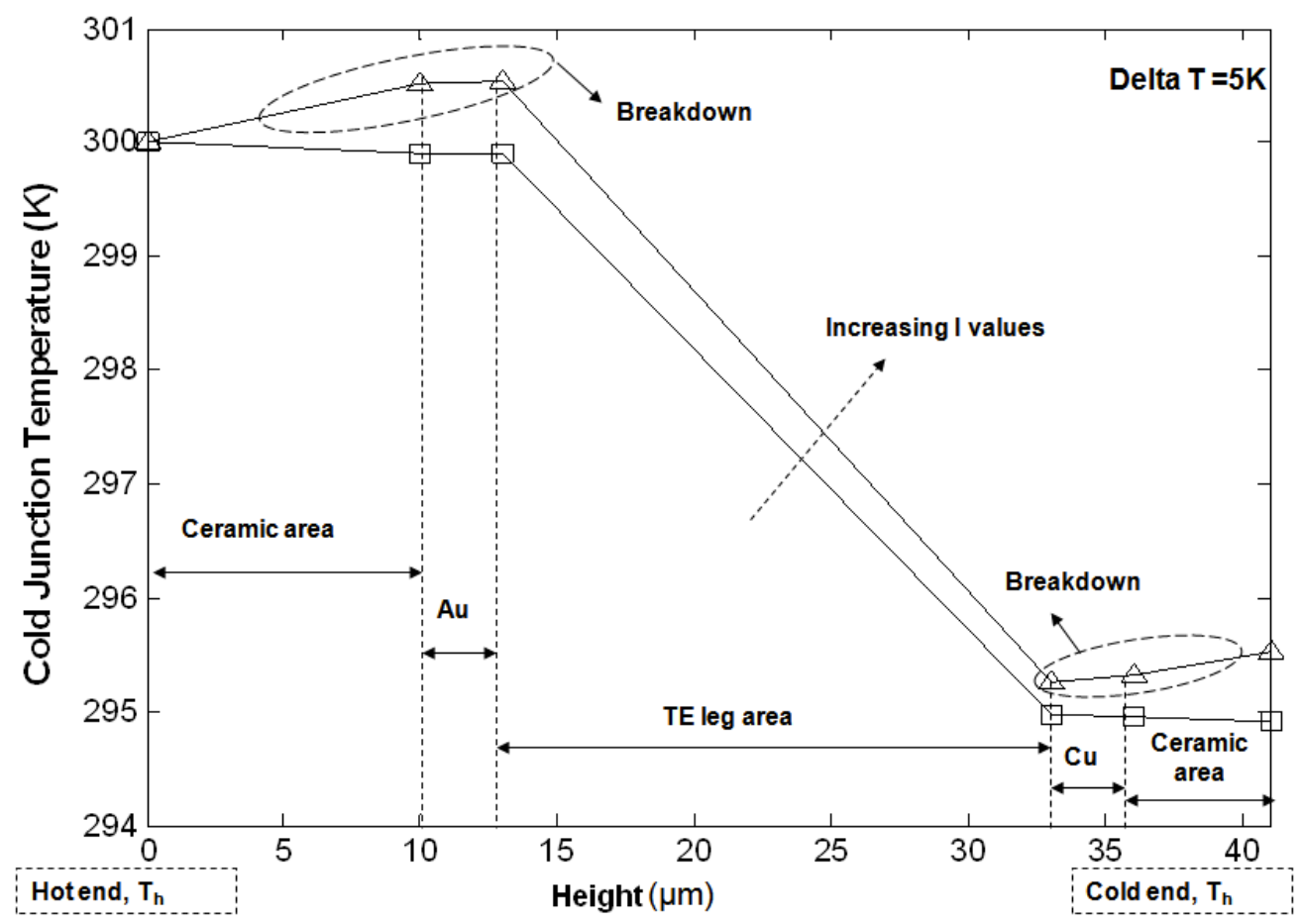

Fig. (4). Graphical representation of the secondary breakdown region. Here, a temperature gradient can be defined as beneficial when there is a constant decrease in temperature on moving progressively from the hot to cold junction in a TE cooler and the ceramic and the metal interconnects fail to maintain a beneficial temperature gradient. 


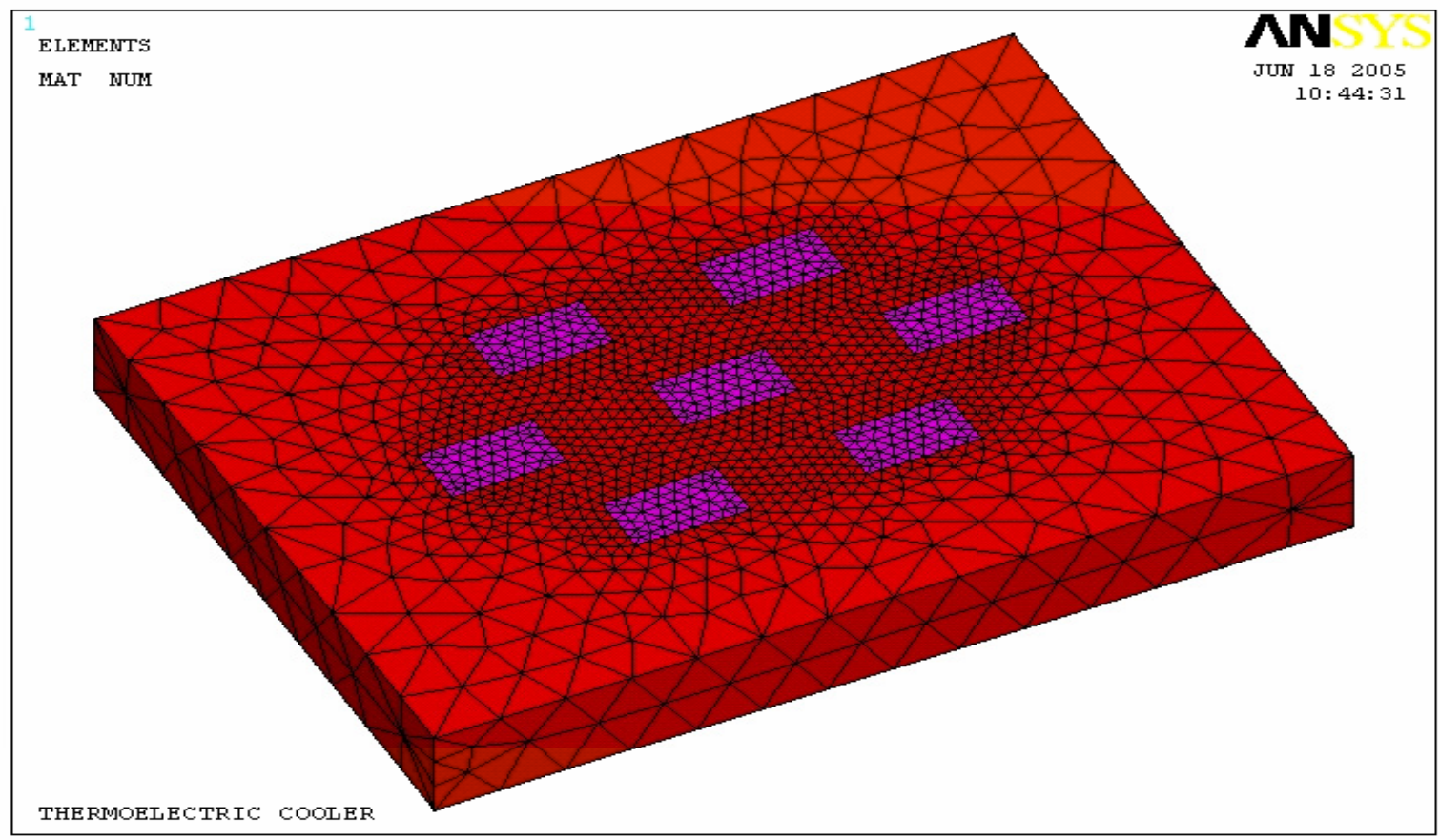

Fig. (5). The 3D thermal model scheme with symmetrical distribution of $7 \mu$ TECs.

achievable distance between the two $\mu$ TEC legs to $10 \mu \mathrm{m}$. Thus, the final optimized geometrical device parameters of the individual $\mu$ TECs in the array are obtained and are as given in Table $\mathbf{1}$.

The 3-D ANSYS ${ }^{\circledR}$ model was also used to understand the influence of the spacing between $\mu$ TECs on the device performance. As expected under similar operating conditions, decreasing the distance between $\mu$ TECs decreases the variations in the temperature field and to achieve a uniform temperature throughout the device the $\mu$ TECs should be spaced as closely as possible. This allows uniform cooling of the biological cells placed above the $\mu$ TECs array with all the $\mu \mathrm{TEC}$ operating under same conditions. However, as stated earlier, we propose to use this device to establish discrete and distinct temperatures between 2 adjacent cells embedded in an extracellular matrix. Thus, it becomes essential to identify the minimum possible spacing between two adjacent $\mu$ TECs that will allow us to establish discrete temperatures within each $\mu$ TEC with minimal interference between their respective temperature fields. To do so, we considered a system with two $\mu$ TECs separated from each other at various distances $(10$ to $100 \mu \mathrm{m})-$ see Fig. 6B. We then defined the minimal distance for establishing distinct temperature profiles within each $\mu$ TEC as: "the minimum distance required to maintain the temperature at the midpoint between the $\mu$ TECs at $60 \%$ (or lower) of $\Delta \mathrm{T}_{\mathrm{i}} ; \Delta \mathrm{T}_{\mathrm{i}}=\mathrm{T}_{\mathrm{h}}-\mathrm{T}_{\mathrm{c}}$ of each individually addressable $\mu$ TEC". ANSYS simulations were performed by maintaining $\mu \mathrm{TEC}_{1}$ at a constant $\Delta \mathrm{T}_{1}$ and subjecting $\mu \mathrm{TEC}_{2}$ to varying current within the desired operating range of $0.1-1 \mathrm{~mA}$. Under varying current conditions, the minimal required distance of separation between individual $\mu$ TECs in the array was thus found to be $50 \mu \mathrm{m}$ (Fig. 6B). Hence, for adjacent $\mu$ TECs to operate with minimal interference between their respective temperature fields it is required to place them at least $50 \mu \mathrm{m}$ apart. Surprisingly, this value of $50 \mu \mathrm{m}$ is in reasonably good agreement with intercell spacing in a typical artificial tissue matrix composed of fibroblasts [24], suggesting that the proposed device is suitable for bio-applications. Additionally, the temperature change $(\Delta \mathrm{T} \sim 4 \mathrm{~K})$ predicted using the model, is sufficient for most hypothermic experiments on biosystems (for example, a system at $37^{\circ} \mathrm{C}$ can be heated to $41^{\circ} \mathrm{C}$ or cooled to $33^{\circ} \mathrm{C}$, a reasonably large temperature range for furthering our understanding of localized heating and cooling on cells embedded in an extracellular matrix). However, further improvements are clearly needed to the proposed device to make it suitable for a wider variety of temperature dependent bioapplications, especially applications at subzero temperatures. These improvements, include the possible use of $\mathrm{Bi}-\mathrm{Te}$ nanowires and nanotubes to increase the coefficient performance of the device, the use of multiplexing or multistage devices arranged in series, and improvements to the material properties of the $\mu$ TEC leg elements.

\section{CONCLUSIONS}

A lumped parameter model was developed and numerical simulations were carried out to investigate the influence of critical parameters related to integrated biological cell and the single stage $\mu$ TECs system under steady state conditions. The effects of electrical contact resistance and leg shape were included. Results show that the smaller height and larger length of the $\mu$ TEC leg element resulted in better cooling capabilities of the system. It has also been shown that a smaller interconnect height is more beneficial for achieving a better $\Delta \mathrm{T}$ across the $\mu \mathrm{TEC}$ system. A new limitation which we denote as "the secondary breakdown current" was observed for $\mu$ TECs due to a thermal breakdown in the ceramic and metallic interconnects. This secondary breakdown 

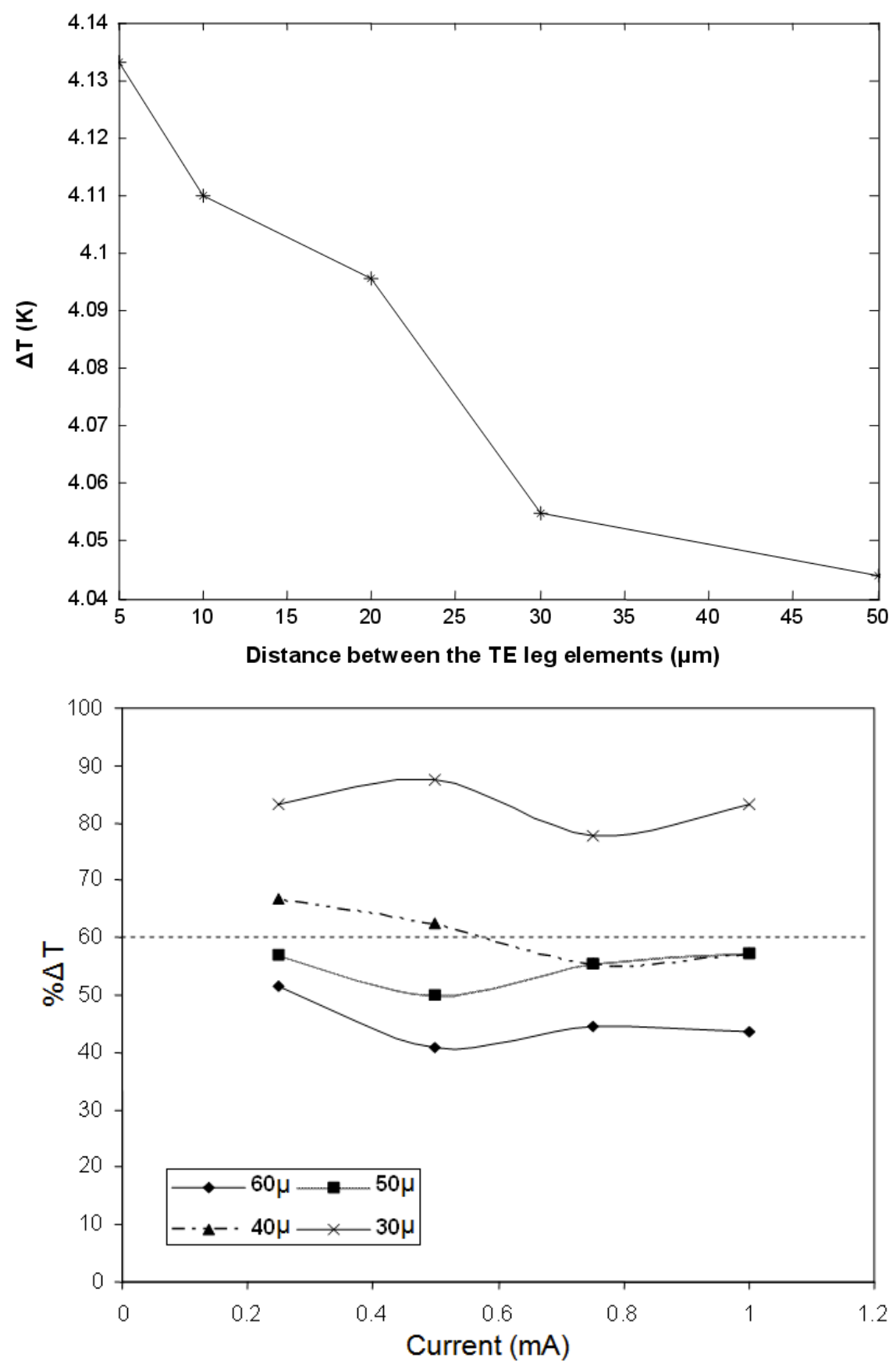

Fig. (6). Influence of the spacing between the two TE on each $\mu$ TEC's (Fig. A, top) and a representation of the minimal distance of separation between $2 \mu$ TECs. The temperature at the midpoint between the two $\mu$ TECs is maintained below $60 \%$ of $\Delta \mathrm{T}_{2}$ only when they are placed at least $50 \mu \mathrm{m}$ away from each other (Fig. B, bottom).

current is much lower than the primary breakdown due to Joule's heating and was found to be $<1 \mathrm{~mA}$ for our device. Using the geometrical analysis results obtained from lumped parameter model, a more detailed 3-D finite element model was developed using ANSYS $^{\circledR}$. The ANSYS $^{\circledR}$ model was used to determine the optimal spacing between the leg elements with an $\mu$ TEC and the interaction between $\mu$ TECs. Current and future studies include fabrication and characterization of individually addressable $\mu$ TECs located at discrete intervals in an array.

\section{ACKNOWLEDGEMENTS}

Support from the Department of Mechanical Engineering at LSU is gratefully acknowledged.

\section{REFERENCES}

[1] Ioffe AF. Semiconductor thermoelements and thermoelectric cooling. London: Infosearch; 1957.

[2] Goldsmid HJ. Electronic refrigeration (London: Pion). 1986.

[3] Rowe DM. CRC handbook of thermoelectrics. Boca Raton, Florida, USA: CRC press; 1999. 
[4] Landecker K. Improvement of the performance of Peltier junctions for thermoelectric cooling. J Phys C Solid State Phys 1970; 3: 2146-50.

[5] Rosi FD, Abeles B, Jensen RV. Materials for thermoelectric refrigeration. J Phys Chem Solid 1959; 10: 191-00.

[6] Sherman B, Heikes RR, Ure RW. Calculation of efficiency of thermoelectric devices. J Appl Phys 1960; 31: 1-16.

[7] Chen K, Gwilliam SB. Heat transfer analysis and optimization of TE (thermoelectric) cooling systems. $12^{\text {th }}$ Int Conf Thermoelectrics, Osaka, Japan; 1993; pp. 395-03.

[8] Ogawa Y. Analysis of thermoelectric conversion system design. Tokyo, Japan: Morikita, Shuppan; 1999.

[9] Lau PG, Buist RJ. Temperature and time dependent finite-element model of a thermoelectric couple. $15^{\text {th }}$ Int Conf Thermoelectrics, 1996; pp. 227-33.

[10] Yamanashi M. New approach to optimum design in thermoelectric cooling systems. J Appl Phys 1996; 80: 5494-02.

[11] Yamanashi M. Response to Comment on 'a new approach to optimum design in thermoelectric cooling systems'. J Appl Phys 1997; 82: 6370-71.

[12] Chen J, Schouten JA. Comment on 'a new approach to optimum design in thermoelectric cooling systems'. J Appl Phys 1997; 82: 659-60.

[13] Huang BJ, Chin CJ, Chuan CL. Design method of thermoelectric cooler. Int J Refrig 2000; 23: 208-18.

[14] Chen J, Lin B, Wang H, Lin C. Optimal design of a multi-couple thermoelectric generator. Semicond Sci Technol 2000; 15: 184-88.

Received: March 1,2007

Accepted: April 17, 2007
[15] Yao DJ, Kim C, Chen G. Design of thin-film thermoelectric microcoolers. ASME Heat Transfer Div Publ HTD 2000; 366: 341-45.

[16] Xuan XC. Optimum design of a thermoelectric device. Semicond Sci Technol 2002; 17: 114-19.

[17] Xuan XC, Nag KC, Yap C, Chua HT. Optimization and thermodynamic understanding of conduction-cooled Peltier current leads. Cryogenics 2002; 42:141-45.

[18] Yao DJ, Kim CJ, Chen G, Fleurial, JP, Lyon HB. Spot cooling using thermoelectric microcoolers. Int Conf Thermoelectr ICT Proc. Baltimore, MD, USA, 1999; pp. 256-59.

[19] Ju YS, Ghoshal U. Study of interface effects in thermoelectric microrefrigerators. J Appl Phys 2000; 88: 4135-39.

[20] Yang R, Chen G, Snyder GJ, Fleuriel JP. Geometric effects on the transient cooling of thermoelectric coolers. Materials Research Society Symposium - Proceedings, 2002; 691: 281-86.

[21] Fan X, LaBounty C, Vashaee D, et al. High cooling power density $\mathrm{SiGe/Si} \mathrm{micro-coolers.} \mathrm{Electron} \mathrm{Lett} \mathrm{2001;} \mathrm{27:} \mathrm{126-27.}$

[22] LaBounty C, Shakouri A, Bowers JE. Design and characterization of thin film microcoolers. J Appl Phys 2001; 89: 4059-04.

[23] Zhang Y, Vashee D, Christofferson J, et al. 3D electrothermal simulation of heterostructure thin film micro-coolers. ASME Adv Energy Syst Div Publ AES 2003; 43: 39-48.

[24] He Y, Devireddy RV. An inverse approach to determine the permeability of cryoprotective agents and water in artificial tissues. Ann Biomed Eng 2005; 33: 709-718. 